\title{
Infiltration Capacity of Roadside Filter Strips with Non-Uniform Overland Flow
}

By: María García-Serrana (corresponding author) (garci683@umn.edu) ${ }^{1}$, John S. Gulliver

(gulli003@umn.edu) ${ }^{1}$, and John L. Nieber (nieber@umn.edu) ${ }^{2}$

\begin{abstract}
The side slope to a roadside swale (drainage ditch) constitutes a filter strip that has potential for infiltration of road runoff, thereby serving as a stormwater quantity and quality control mechanism. A total of thirty-two tests were performed during three seasons in four different highways located in the Minneapolis-St. Paul metropolitan area, MN to analyze the infiltration performance of roadside filter strips and the effect of fractional coverage of water on infiltration. Three different application rates were used in the experiments. All the tests showed that water flow on the lateral slope of a roadside swale is concentrated in fingers, instead of sheet flow, at the typical road runoff intensities for which infiltration practices are utilized to improve surface water quality. A linear relationship between flux of water from the road and fraction of wetted surface was observed, for the intensities tested.
\end{abstract}


The average percentage infiltration of the medium road runoff rate $\left(1.55 \times 10^{-4} \mathrm{~m}^{2} / \mathrm{s}\right.$, without direct rainfall) experiments performed in fall was $85 \%$ and in spring $70 \%$. For the high road runoff rate $\left(3.1 \times 10^{-4} \mathrm{~m}^{2} / \mathrm{s}\right.$, without direct rainfall) tests the average amount of water infiltrated was $47 \%$ and for the low road runoff rate $\left(7.76 \times 10^{-5} \mathrm{~m}^{2} / \mathrm{s}\right.$, without direct rainfall $)$ tests it was $69 \%$, both set of tests performed in spring and summer. The saturated hydraulic conductivity of swale soil was high, relative to the values typical of laboratory permeameter measurements for these types of soils. This is believed to be due to the macropores generated by vegetation roots, activity of macrofauna (e.g. earthworms), and construction/maintenance procedures. The trend was to have more infiltration when the saturated hydraulic conductivity was higher and for a greater side slope length, as expected. The vegetation, type of soil and length of the side slope are important to consider for constructing and maintaining roadside swales that will be efficient as stormwater control measures. These measurements indicate that the filter strip portion of a roadside swale typically infiltrates a substantial fraction of road runoff. However, the measurements do not incorporate the influence of direct rainfall upon the infiltration into filter strips.

Keywords: Filter strip; infiltration; overland flow; saturated hydraulic conductivity; roadside drainage ditch, stormwater control measure. 


\section{1. Introduction}

2 A growing trend in stormwater management is to include techniques that reduce runoff volumes

3 and improve runoff water quality in addition to reducing the peak flow rate. Such techniques are

4 called low impact development (LID) practices or Green Infrastructure (GI) and are typically

5 designed to reduce runoff and to mimic a site's predevelopment hydrology. These practices

6 include filter strips and vegetated drainage ditches (grassed swales), among others. They improve

7 water quality by infiltration, filtration, and sedimentation. For roadway runoff flowing into a

8 grassed swale, volume reduction occurs primarily through infiltration into the soil, either as the

9 water flows over the side-slope in a direction perpendicular to the roadway into the swale or

10 down the length of the swale channel parallel to the roadway. Most of the prior research on

11 swales was on the channel portion, not the side slope. According to Barrett et al. (1998), as long

12 as the road runoff is allowed to flow directly down the side slope into the swale, the side slope

13 acts as a filter strip. Pollutant removal can occur by sedimentation of solid particles onto the soil

14 surface, filtration of solid particles by vegetation, or infiltration and adsorption/degradation of

15 pollutants dissolved in the runoff (Abida and Sabourin, 2006). The infiltration capacity of each

16 swale will depend on many variables and each swale should be examined individually (Ahmed et

17 al., 2015).

18 Using synthetic runoff, Deletic and Fletcher (2006) studied a 5m long grass strip with a 7.8\%

19 average longitudinal slope and found 33\% of average infiltration rates (as a percentage of the

20 inflow) for the tests where the inflow water was mixed with sediment and 56\% where the inflow

21 was clean. A study by Liu et al. (2016) analyzed the synthetic runoff from 5m long loamy

22 hillslopes ( $15^{\circ}$ and $30^{\circ}$ slopes) with different vegetation treatments on a newly built unpaved 
23 road. The mean runoff coefficient for the grassed side slopes was less than 0.1 . The runoff

24 coefficient was found to be correlated with the saturated hydraulic conductivity, vegetation

25 cover, root weight density, and root length density.

26 Multiple studies have monitored volume reduction with swales subject to natural storm events.

27 For example, Lancaster (2005) monitored infiltration along roadside swales in Washington, and

28 reported $100 \%$ infiltration within the first two meters from the edge of pavement in one site (36

29 precipitation events). At another site, $67 \%$ of the events (18 precipitation events) had no

30 observed runoff. Ahearn and Tveten (2008) investigated the performance of four 41 year-old,

31 unimproved roadside swales. The results from the monitoring station located at 4 meters from

32 the edge of pavement showed $66 \%$ to $94 \%$ runoff volume reduction.

33 The main difference between the side slope to a roadside grassed swale and traditional filter

34 strips is the slope, the former having much greater incline. Hunt et al. (2010) investigated the

35 volume reduction capability of a $44.8 \mathrm{~m}(147 \mathrm{ft})$ vegetative filter strip with a $1.25 \%$ slope over a

36 16-month period and 23 rainfall events. Total volume reduction over the monitoring period was

$3785 \%$ and the 3 events that produced runoff at the base of the swale had total rainfall depths

38 greater than $40 \mathrm{~mm}$ (1.6 inches). Knight et al. (2013) monitored different vegetative filter strips

39 with a level spreader. The strips had $1 \%$ slope, sandy loam/clay loam soils, and an estimated 0.1

$40 \mathrm{~cm} / \mathrm{h}$ hydraulic conductivity. The $8 \mathrm{~m}$ long strip had an average runoff reduction of $36 \%$ while

41 the $20 \mathrm{~m}$ long strip had a $59 \%$ average volume reduction.

42 Barrett (1998) indicated that in practice, flow in swales tends to concentrate in small, incised

43 channels that reduce their effectiveness in removing constituents dissolved in highway runoff. Le

44 Bissonnais et al. (2004) reported a reduction in the efficiency of grassed strips when the runoff

45 was concentrated in rills and the surface was not completely covered by sheet flow. Poletika et 
al. (2009) investigated the effect of upper boundary application flow rate and flow concentration

47 on percentage volume reduction of a vegetative filter strip. An application flow rate of

48 approximately $2.09 \times 10^{-4} \mathrm{~m}^{2} / \mathrm{s}$ had a mean volume reduction of $41 \%$ and an application flow rate

49 of $4.78 \times 10^{-4} \mathrm{~m}^{2} / \mathrm{s}$ had a $34 \%$ volume reduction. The plot with concentrated flow (covering $10 \%$

50 of the surface width) had a volume reduction of $16 \%$.

51 Results from previous research on infiltration performance of swales and filter strips have great

52 variability on percentage of water infiltrated, probably because they have a wide range of inputs,

53 use different methods to apply the water, and have different extents of concentrated flow. They

54 generally vary in location, swale characteristics and type of soil, precipitation intensity and

55 duration, drainage area, and whether the water is input as natural or artificial rain, or

56 concentrated runoff. Based on previous studies, it is believed that the infiltration performance of

57 swales is linked to infiltration capacity of the soil, initial soil moisture content, ratio of

58 impervious drainage area-swale area, length and width of the vegetated area, slope, type of flow

59 down the side slope of the swale (sheet or concentrated flow), and total depth and intensity of

60 precipitation. Consequently, the experiments presented in this research take into account the

61 most important factors for typical roadside swales side slopes. According to Asleson et al.

62 (2009), monitoring the performance of full-scale stormwater treatment devices during real storm

63 events is difficult to do with accuracy; alternatively performance tests of field installation using

64 simulated rainfall events is a more reliable approach. In this research, the effect of non-uniform

65 overland flow under a range of generated runoff fluxes on infiltration rates is tested. The goal is

66 to analyze the volume reduction achieved by roadside filter strips (side slope of the swale) under

67 different rainfall regimes using simulated runoff. 


\section{Method}

\subsection{Site Selection and Preparation}

70 The four highways selected for this study were analyzed previously in field infiltration

71 measurements study by Ahmed et al. (2015): Hwy 13 (Hwy 13 and Oakland Beach Ave. SE,

72 Savage, MN), Hwy 47 (University Ave. NE and 83rd Ave. NE, Fridley MN), Hwy 55 (Snelling

73 Ave. and County Rd. E, Arden Hills, MN), and Hwy 77 (Cedar Ave. and E 74th St. North of

74 Hwy 494, Bloomington, MN). These swales are between 30 and 50 years-old, constructed by the

75 Minnesota Department of Transportation. Two locations were tested in each highway, 6-10 m

76 apart, chosen to assure safety and ease of access. All of the side slopes had $90 \%$ or more

77 vegetation cover, which is sufficient to consider these vegetated. For water quality purposes, for

78 example, CALTRANS (2003) found that "a minimum vegetative cover of about $65 \%$ is required

79 for pollutant concentration reduction to occur, and a rapid decline in performance occurs below

80 about $80 \%$." The soil types studied (loam, loamy sand, sandy loam, and sandy clay loam)

81 correspond to hydrologic soil groups A, B and C (NRCS, 2009).

82 For the field tests, the grass was mowed with a lawn mower and shears were used to finish

83 cutting the surface vegetation to a height of approximately $1 \mathrm{~cm}$. The grass clippings were

84 collected in the lawn mower bag and the remainder was cleared with a bamboo rake (Figure 1).

85 The water depths during the tests were lower than the height of the remaining vegetation. The

86 roots of the vegetation were not modified, leaving the existing soil matrix and soil macroporosity

87 in the original state. Surface roughness data was collected using a pin meter operated on a fixed

88 frame. Cross-sectional pin meter measurements were documented with a camera, collecting the

89 relief every $10.2 \mathrm{~cm}$ (4 in) along the entire length of the swale side slope. 
91 Three different boundary flux rates $\left(q_{b}\right)$ were used (Table 1), equivalent to a uniform rainfall

92 intensity of $2.8 \mathrm{~cm} / \mathrm{h}, 5.6 \mathrm{~cm} / \mathrm{h}$, and $11.2 \mathrm{~cm} / \mathrm{h}$ intensity over a $10 \mathrm{~m}$ wide road and shoulder,

93 assumed typical for a road with 2 lanes. Water equivalent to the road runoff intensity from each

94 of these events was applied to a strip width of $0.9 \mathrm{~m}$ at the top of the slope along the edge of the

95 shoulder of the road. The water was pumped with a hose from a reservoir with a submersible

96 pump. Discharges were adjusted with a valve, volumetrically calibrated before every experiment

97 to $4.3,8.5$, and $17 \mathrm{~L} / \mathrm{min}$. The water was pumped to a plastic box with a rectangular weir (Figure

98 1). To enable visualization of the flow patterns, the water was mixed with industrial kaolin

99 (median particle size $0.5 \mu \mathrm{m}$ ), a clay mineral, using a paint mixer to achieve a $13 \mathrm{~g} / \mathrm{L}$ uniform

100 concentration. The total volume of water for each experiment was $255 \mathrm{~L}$. The water patterns

101 were recorded by installing a camera with a mounting pole set in the channel of the swale; the

102 pole had an adjustable height and the average height at which the camera was set was $2.5-3 \mathrm{~m}$.

103 The camera was programmed to take one picture every five seconds. A $1 \mathrm{x} 1 \mathrm{~m}$ mesh frame was

104 installed on the swale to facilitate corrections of angle distortions in the pictures taken (Figure 2

105 a).

Table 1 Boundary flux $\left(q_{b}\right)$, intensity $(I)$, assumed width of the road $\left(W_{r}\right)$, and duration of the test corresponding to the low, medium and high flux experiments.

\begin{tabular}{|c|c|c|c|c|}
\cline { 2 - 5 } \multicolumn{1}{c|}{} & $\boldsymbol{q}_{\boldsymbol{b}}\left(\mathrm{m}^{2} / \mathbf{s}\right)$ & $\boldsymbol{I}(\mathbf{c m} / \mathbf{h})$ & $W_{\boldsymbol{r}}(\mathbf{m})$ & Duration (min) \\
\hline Low flux & $7.76 \times 10^{-5}$ & 2.79 & 10 & 60 \\
\hline Medium flux & $1.55 \times 10^{-4}$ & 5.59 & 10 & 30 \\
\hline High Flux & $3.10 \times 10^{-4}$ & 11.18 & 10 & 15 \\
\hline
\end{tabular}


108 The water not infiltrated by the swale was collected from a clay lined trench dug at the bottom of 109 the side slope connected to a receiving bucket. The total volume of water that was not infiltrated

110 (runoff) was recorded, as well as the runoff rate when the system reached steady state, or when

111 the volume collected over 30 second intervals was constant by the end of the tests. The following

112 data were collected:

113 - Micro-topography of the surface,

114 - Total volume of runoff water (water not infiltrated in the side slope of swale),

115 - Intensity of runoff flow,

116 - Wetted surface area over time,

117 - Soil texture and bulk density,

118 - Initial soil moisture content, and

119 - Saturated hydraulic conductivity and effective wetting front suction.

120 For each highway, two soil cores of $13 \mathrm{~cm}$ length from the surface were collected during fall

1212014 , using a cylindrical core sampler to examine bulk density and porosity (ASTM D2937-10).

122 Those cores were used to investigate soil texture; the soil samples were processed using the wet 123 sieving analysis (ASTM D6913) and hydrometer analysis (ASTM D422) to determine \% clay, \%

124 silt and \% sand in each sample. Before each test, three soil samples were collected to determine 125 initial soil moisture content (ASTM D2216). The Green Ampt (1911) parameters, saturated 126 hydraulic conductivity and wetting-front suction $(\psi)$ in the upper $25 \mathrm{~cm}$ were estimated at the 127 end of the field tests using the MPD infiltrometer method (Asleson et al. 2009; Olson et al., 128 2013; Ahmed et al. 2014). For this, twenty measurements of falling head were taken per highway 129 and utilized in the MPD spreadsheet to compute the saturated hydraulic conductivity and the 130 capillary suction of the soil ahead of the wetting front. 
131 To evaluate the wetted area, images were processed following a five step procedure using the

132 software ImageJ, an image processing and analysis software. First, based on the frame positioned

133 in the field, the image (Figure 2a) was orthogonally projected (Figure 2b), using the ImageJ

134 plugin Projective_Mapping with a bilinear approximation. Second, the picture was transformed

135 into an 8-bit grey scale. Afterwards, a study area was selected and cropped based on the spread

136 of the water along the slope. Then, a Fuzzy Contrast Enhancement (Figure 2c) plugin (Alestra

137 and Battiatto, 2008) was used to differentiate the wetted from the dry area. Finally, a

138 thresholding method that binarises 8-bit images was implemented to select the wetted area. The

139 preferred technique was the "Intermodes" method (Prewitt et al., 1966), which assumes a

140 bimodal histogram (Figure $2 \mathrm{~d}$ ). Verification of the images was made by visually observing the

141 locations of the water on the slope and comparing them to the information taken from the

142 photographs; the results were similar.

\section{Results and Analysis}

144 The analysis is based on a total of 32 tests performed during fall 2014, spring 2015, and summer 1452015 on highways: 51, 77, 47, and 13 in the Minneapolis-St. Paul, USA metropolitan area. The 146 duration of the low, medium, and high application rates was 60, 30 and 15 minutes, respectively.

\subsection{Dimensionless Infiltration Parameters}

148 Infiltration measurements were made at two strips in each of four sites. Representative

149 dimensionless parameters will be used to generalize the results. These were chosen from

150 knowledge of the physical processes. The first parameter is a relative volume of infiltration: 
152 ; where $V_{\text {inf }}$ is the volume infiltrated and $V_{\text {in }}$ is the input volume. When $\mathrm{V}_{\mathrm{i}}{ }^{*}$ is equal to one, all of

153 the runoff from the road has infiltrated in the side slope of the swale. The second parameter is a

154 relative saturated hydraulic conductivity:

$K_{s}^{*}=\frac{K_{\text {sat }}}{I} \frac{W_{S}}{W_{R}}$

156 ; where $K_{\text {sat }}$ is a representative saturated hydraulic conductivity for the side slope, $I$ is average

157 rainfall intensity, $W_{S}$ is the width of the swale perpendicular to the road, and $W_{R}$ is the width of

158 the road draining into the swale. Infiltration fraction will typically increase with $\mathrm{K}_{\mathrm{s}}{ }^{*}$. In a sheet

159 flow, $\mathrm{K}_{\mathrm{s}}{ }^{*}$ equal to one will result in complete infiltration of the water. This factor does not take

160 into account concentrated flow, which would reduce $\mathrm{V}_{\mathrm{i}}{ }^{*}$, or soil moisture deficit, which would

161 increase $\mathrm{V}_{\mathrm{i}}{ }^{*}$. The field experiments results presented show the relationship between $\mathrm{K}_{\mathrm{s}}^{*}$ and $\mathrm{V}_{\mathrm{i}}{ }^{*}$,

162 taking into account concentrated flow and initial soil moisture content.

\subsection{Characteristics of the Roadside Filter Strips}

164 Table 2 provides information about the sections of the roadside filter strips examined during the

165 field experiments. Using the percentages of clay, silt and sand in a textural triangle (USDA,

166 2014) the soil texture class in the upper $13 \mathrm{~cm}$ was determined. Rows with two soil textures

167 (Hwy 51, 47, and 13) indicate that among the eight soil cores samples, there were both textural

168 classes of soil. The slope and length of the side slope perpendicular to the road were measured at

169 each site. The values of $\mathrm{K}_{\mathrm{sat}}$ were adjusted to $20^{\circ} \mathrm{C}$ by multiplying the measured $\mathrm{K}_{\mathrm{sat}}$ at a given

170 temperature (T) by the viscosity correction factor $\eta_{T} / \eta_{20}{ }^{\circ} \mathrm{C}$; where $\eta_{\mathrm{T}}$ is the viscosity of water at a

171 certain temperature.

172 The representative saturated hydraulic conductivity for infiltration given in Table 2 is computed

173 as: 
175 ,where the arithmetic $\left(K_{\text {sat Arithmean }}\right)$ and geometric $\left(K_{\text {sat Geomean }}\right)$ mean values were calculated from

17620 measurements of saturated hydraulic conductivity using the MPD infiltrometer (Ahmed et al.,

177 2015) performed on the strips tested. Equation 3 , with $\beta=0.32$, was derived by fitting to a

178 simulation that used $268 K_{\text {sat }}$ measurements at 12 sites by Weiss and Gulliver (2015). They found

179 that a linear combination of $K_{\text {sat }}$ arithmetic and geometric mean values more accurately

180 represented the observed aggregated infiltration in the soil of stormwater treatment practices,

181 including swales.

182 Table 2 Characteristics of the swales studied based on soil cores samples, estimations of saturated 183 hydraulic conductivity $\left(\right.$ at $\left.20^{\circ} \mathrm{C}\right)$, and length and slope of the sections used in the experiments.

$184 *$ Coefficient of variation in parenthesis.

\begin{tabular}{|c|c|c|c|c|c|c|c|c|c|c|c|}
\hline & $\begin{array}{c}\text { Soil } \\
\text { Texture }\end{array}$ & $\begin{array}{c}\text { Arithmetic } \\
\text { mean of } \\
\text { Ksat } \\
(\mathbf{c m} / \mathbf{h})(\text { at } \\
\left.\mathbf{2 0}^{\circ} \mathrm{C}\right)\end{array}$ & $\begin{array}{c}\text { Geometric } \\
\text { mean of } \\
\text { Ksat } \\
(\mathbf{c m} / \mathbf{h})(\text { at } \\
\left.20^{\circ} \mathrm{C}\right)\end{array}$ & $\begin{array}{c}\text { Ksat } \\
(\mathrm{cm} / \mathrm{h}) \\
\text { (based } \\
\text { on Eq. } \\
\text { 3) }\end{array}$ & $\begin{array}{c}\text { HSG } \\
\text { (base } \\
\text { d on } \\
\text { Eq. 3) }\end{array}$ & $\begin{array}{c}\text { Bulk } \\
\text { Density } \\
\text { (g/cm3) }\end{array}$ & $\begin{array}{l}\text { Poro- } \\
\text { sity } \\
(\%)\end{array}$ & $\begin{array}{l}\text { Average } \\
\text { Initial } \\
\text { Soil } \\
\text { Moisture } \\
\text { Content } \\
\text { (Fall) } \\
(\%)\end{array}$ & $\begin{array}{c}\text { Average } \\
\text { Initial Soil } \\
\text { Moisture } \\
\text { Content } \\
\text { (Spring) } \\
(\%)\end{array}$ & $\begin{array}{l}\text { Slo } \\
\text {-pe }\end{array}$ & $\begin{array}{c}\text { Length } \\
\text { studied } \\
\text { (cm) }\end{array}$ \\
\hline $\begin{array}{c}\text { Hwy } \\
51\end{array}$ & $\begin{array}{c}\text { Loam } \\
\text { /sandy } \\
\text { loam } \\
\end{array}$ & $5.1(1.44)^{*}$ & 2.8 & 3.5 & B & 1.1 & 0.56 & 0.15 & 0.30 & $5: 1$ & 406 \\
\hline $\begin{array}{c}\text { Hwy } \\
77\end{array}$ & $\begin{array}{l}\text { loamy } \\
\text { sand }\end{array}$ & $7.5(0.94)^{*}$ & 4.9 & 5.7 & A & 1.2 & 0.56 & 0.15 & 0.20 & $5: 1$ & 407 \\
\hline $\begin{array}{c}\text { Hwy } \\
47\end{array}$ & $\begin{array}{l}\text { loamy } \\
\text { sand } \\
\text { /sandy } \\
\text { loam }\end{array}$ & $4.9(1.29)^{*}$ & 2.8 & 3.5 & B & 1.2 & 0.54 & 0.12 & 0.27 & $5: 1$ & 779 \\
\hline $\begin{array}{c}\text { Hwy } \\
13\end{array}$ & $\begin{array}{c}\text { Loam } \\
\text { /sandy } \\
\text { clay } \\
\text { loam }\end{array}$ & $6.1(1.87)^{*}$ & 3.2 & 4.1 & A & 1.1 & 0.58 & 0.13 & 0.29 & $4: 1$ & 422 \\
\hline
\end{tabular}

185

187 Table 3 summarizes the results of the different experiments performed at the highway 51, 77, 47,

188 and 13 sites during fall 2014, and spring and summer 2015, with percentage of volume

189 infiltrated, start time of runoff (flow not infiltrated entering the channel) and approximate runoff 
190 rate (at the bottom of the side slope) after steady state in runoff was approached for the different 191 cases studied. The field tests were performed in this order: medium flux (fall 2014), medium flux, 192 low flux, and high flux (spring and summer 2015). 
193

194

195

196

Table 3 Results of the field experiments in chronological order at the four highways selected during the three different seasons using three different intensities of boundary flux. The fall experiments were performed in 2014 and the spring and summer tests in 2015. The (-) indicates no runoff generation, *Tests affected by construction and ${ }^{*}$ Site with plains pocket gopher holes.

\begin{tabular}{|c|c|c|c|c|c|c|c|}
\hline & Season & $\begin{array}{l}\text { Boundary } \\
\text { Fluxes }\end{array}$ & Site & $\begin{array}{l}\text { Runoff } \\
\text { start time } \\
\text { (min) }\end{array}$ & $\begin{array}{c}\text { Rate runoff } \\
\text { (steady } \\
\text { state) } \\
(\mathrm{L} / \mathrm{min}) \\
\end{array}$ & $\begin{array}{c}\% \\
\text { Wetted } \\
\text { Area }\end{array}$ & $\begin{array}{c}\% \\
\text { Infiltrated }\end{array}$ \\
\hline \multirow{8}{*}{$\begin{array}{c}\text { Hwy } \\
51\end{array}$} & \multirow{2}{*}{ Fall } & \multirow{2}{*}{$\begin{array}{l}\text { Medium } \\
\text { Flux }\end{array}$} & Site 1 & 17 & 2.75 & $84 \%$ & $86.5 \%$ \\
\hline & & & Site 2 & 9 & 3.1 & $69 \%$ & $74.1 \%$ \\
\hline & \multirow{6}{*}{ Spring } & \multirow{2}{*}{$\begin{array}{l}\text { Medium } \\
\text { Flux }\end{array}$} & Site 1 & 11.6 & 5.5 & $61 \%$ & $61.4 \%$ \\
\hline & & & Site 2 & 12 & 4.2 & $69 \%$ & $72.4 \%$ \\
\hline & & \multirow{2}{*}{ Low Flux } & Site $1 *$ & 8.8 & 3.1 & $67 \%$ & $59.2 \%$ \\
\hline & & & Site $2 *$ & 5.6 & 3 & $77 \%$ & $62.1 \%$ \\
\hline & & \multirow{2}{*}{ High Flux } & Site $1 *$ & 1.7 & 16.25 & $79 \%$ & $32.2 \%$ \\
\hline & & & Site $2 *$ & 1.4 & 16.5 & $90 \%$ & $32.7 \%$ \\
\hline \multirow{8}{*}{$\begin{array}{c}\text { Hwy } \\
77\end{array}$} & \multirow{2}{*}{ Fall } & \multirow{2}{*}{$\begin{array}{l}\text { Medium } \\
\text { Flux }\end{array}$} & Site 1 & 6.3 & 3.75 & $64 \%$ & $64.8 \%$ \\
\hline & & & Site 2 & 15 & 4.2 & $70 \%$ & $76.6 \%$ \\
\hline & \multirow{6}{*}{ Spring } & \multirow{2}{*}{$\begin{array}{c}\text { Medium } \\
\text { Flux }\end{array}$} & Site 1 & 9 & 4.85 & $66 \%$ & $61.8 \%$ \\
\hline & & & Site 2 & 8.8 & 4.75 & $54 \%$ & $65.9 \%$ \\
\hline & & \multirow{2}{*}{ Low Flux } & Site 1 & 17.6 & 2.5 & $85 \%$ & $68.9 \%$ \\
\hline & & & Site 2 & 28.8 & 2.5 & $66 \%$ & $72.9 \%$ \\
\hline & & \multirow{2}{*}{ High Flux } & Site 1 & 2 & 16.25 & $82 \%$ & $20.6 \%$ \\
\hline & & & Site 2 & 3.3 & 15 & $88 \%$ & $37.5 \%$ \\
\hline \multirow{8}{*}{$\begin{array}{c}\text { Hwy } \\
47\end{array}$} & \multirow{2}{*}{ Fall } & \multirow{2}{*}{$\begin{array}{l}\text { Medium } \\
\text { Flux }\end{array}$} & Site $1 * *$ & - & - & $75 \%$ & $100 \%$ \\
\hline & & & Site 2 & 27.6 & 0.04 & $83 \%$ & $100 \%$ \\
\hline & \multirow{2}{*}{ Spring } & \multirow{2}{*}{$\begin{array}{l}\text { Medium } \\
\text { Flux }\end{array}$} & Site $1 * *$ & 25 & 1 & $70 \%$ & $98.0 \%$ \\
\hline & & & Site 2 & 9.8 & 4.4 & $77 \%$ & $72.7 \%$ \\
\hline & \multirow{2}{*}{ Summer } & \multirow{2}{*}{ Low Flux } & Site 1** & - & - & $70 \%$ & $100 \%$ \\
\hline & & & Site 2 & 14.8 & 2.5 & $57 \%$ & $65.0 \%$ \\
\hline & \multirow{2}{*}{ Summer } & \multirow{2}{*}{ High Flux } & Site $1 * *$ & 10 & 2.8 & $80 \%$ & $95.0 \%$ \\
\hline & & & Site 2 & 5.9 & 8 & $81 \%$ & $74.9 \%$ \\
\hline \multirow{8}{*}{$\begin{array}{c}\text { Hwy } \\
13\end{array}$} & \multirow{2}{*}{ Fall } & \multirow{2}{*}{$\begin{array}{l}\text { Medium } \\
\text { Flux }\end{array}$} & Site 1 & 18.5 & 2.5 & $77 \%$ & $88.4 \%$ \\
\hline & & & Site 2 & 18.25 & 2.6 & $72 \%$ & $87.0 \%$ \\
\hline & \multirow{2}{*}{ Spring } & \multirow{2}{*}{$\begin{array}{l}\text { Medium } \\
\text { Flux }\end{array}$} & Site 1 & 10.9 & 4.5 & $75 \%$ & $68.4 \%$ \\
\hline & & & Site 2 & 9.2 & 6.9 & $70 \%$ & $59.1 \%$ \\
\hline & \multirow{2}{*}{ Summer } & & Site 1 & 11.8 & 2.82 & $58 \%$ & $60.7 \%$ \\
\hline & & Low Flux & Site 2 & 13 & 2.8 & $57 \%$ & $60.7 \%$ \\
\hline & & & Site 1 & 1.5 & 13 & $85 \%$ & $41.8 \%$ \\
\hline & Summer & High Flux & Site 2 & 1.6 & 13.2 & $80 \%$ & $42.2 \%$ \\
\hline
\end{tabular}


197 During spring 2015, before the low flux tests, the roadside swale of Hwy 51 (both sites) was

198 impacted by the placement of fiber optic cable across the ditch and the nearby construction of

199 County Road E bridge. The surface of the swale had vegetation losses and compaction due to

200 truck and excavation operations, however these factors did not noticeably affect the results. At

201 highway 47, plains pocket gopher (Geomys bursarius) holes were observed at site 1, and the

202 infiltration rates at this site were high, with almost $100 \%$ infiltration for all intensities. This is

203 presumed to be a special case due to the plains pocket gopher holes, and will not be included in

204 the analysis. Figure 3 displays the average infiltration percentage for the different intensities. The

205 total equivalent simulated rainfall depth (assumed to be applied over the road) was $2.8 \mathrm{~cm}$ in all

206 tests. The average percentage of water infiltrated during the medium flux experiments performed

207 in fall (8 tests) was $85 \%$, or $2.4 \mathrm{~cm}$ of rain on the road with a $13 \%$ standard deviation. This value

208 is higher than the results observed during spring, with $70 \%$, or $1.95 \mathrm{~cm}$ of rain on the road with a

$20912 \%$ standard deviation. During the high flux experiments ( 8 tests) the average of water

210 infiltrated was $47 \%$, or $1.3 \mathrm{~cm}$ of rain on the road with a $25 \%$ standard deviation. The average

211 water infiltrated during the low flux experiments was $69 \%$, or $1.93 \mathrm{~cm}$ of rain on the road with a

$21214 \%$ standard deviation.

213 Figure 4 provides the mean and standard deviation of the runoff coefficient (ROC) at the end of

214 the experiment, or the rate of runoff at the end of the experiment divided by the boundary flux

215 rate, for each set of tests. The medium flux fall tests had a lower ROC than in the spring,

216 probably because of the low initial soil moisture content for those tests. The infiltration data

217 collected from the medium flux experiments (spring tests) was similar to the low flux tests.

218 These results imply that either there was a reduction in the saturated hydraulic conductivity or an

219 increase of the soil moisture content in the experiments carried out after the first tests (medium 
220 flux) in spring. The similar start time of runoff (Figure 5) and greater ROC (Figure 4) confirm

221 this observation. In the spring tests at highway 13 (Figure 5), the ROC of the low flux test was

2220.66 , higher than the medium flux test 0.53 ; both had similar start times of runoff generation.

223 The possible causes of the relative infiltration reduction are addressed in the Discussion, section

$224 \quad 4.2$

\subsection{Roughness and Wetted Area}

226 The surface of the swales studied neither showed signs of previous erosion nor experienced

227 erosion during the experiments. The measurements taken with the pin meter were translated into

228 a random roughness factor (RR) (Allmaras et al., 1966), which is the standard deviation of

229 surface elevations. The RR reveals the vertical variability in surface elevations (Yang et al.,

230 2013) and was found to be close to the same value for all sites. The average RR (perpendicular to

231 the flow) for all the swales was $4 \mathrm{~mm}$ with a standard deviation of $1 \mathrm{~mm}$. The average $\mathrm{RR}$

232 (parallel to the flow), corrected for slope, was $5 \mathrm{~mm}$, with a standard deviation of $3 \mathrm{~mm}$. For

233 these swales, the variation in RR was minor, and a correlation of RR and wetted area was not

234 attempted.

235 The wetted area appears to be related to the rainfall intensity over the road (Figure 6). A greater

236 intensity, results in more area covered by water. The mean value of percentage wetted area was

$23772 \%$, with a $9 \%$ standard deviation for the selected intensities among the four sites. The

238 maximum percentage wetted area was $90 \%$ and minimum 54\%. An empirical relationship

239 between fraction of wetted area and intensity is given in the following equation, fitted to the field 240 data:

241 Fraction of Wetted Area $=0.00225 \times$ Intensity $[\mathrm{mm} / \mathrm{h}]+0.581$ 
242 Roughness measurements showed that there were minimal preferential pathways in the micro-

243 topography. We hypothesize that the sensitivity of wetted area to intensity is due to the absence

244 of preferential flow features. We also hypothesize that if there were structured micro-topography,

245 oriented in the downslope direction, there would be smaller sensitivity to intensity. The side

246 slopes of the swales were relatively smooth, indicating that the Minnesota Department of

247 Transportation's maintenance procedures were effective.

\subsection{Saturated Hydraulic Conductivity and Infiltration}

249 As expected, the saturated hydraulic conductivity of the soil is observed to be an important factor

250 for infiltration rates. Figure 7 displays the relationship between the percentage infiltrated $\left(\mathrm{V}_{\mathrm{i}}{ }^{*}\right)$

251 and dimensionless parameter $\mathrm{K}_{\mathrm{s}}{ }^{*}$, which is a function of the saturated hydraulic conductivity,

252 rainfall intensity, width of the swale perpendicular to the road, and width of the road. The soil

253 moisture deficit was higher in Test 1 than in the three other tests. The results indicate that $\mathrm{V}_{\mathrm{i}}{ }^{*}$

254 rises sharply below a $\mathrm{K}_{\mathrm{s}}{ }^{*}$ of 0.3 . For $\mathrm{K}_{\mathrm{s}}{ }^{*}$ greater than 0.3 , other factors seem to influence the 255 percent infiltrated in the tests. The influence of soil moisture content, for example, can be seen in 256 the high percent of $\mathrm{V}_{\mathrm{i}}{ }^{*}$ values measured in Test 1 . This influence is discussed in the next 257 subsection.

\subsection{Initial Soil Moisture Content Effect on Infiltration}

259 The initial soil moisture content during the spring experiments was higher than the previous fall,

260 for the same boundary flux. Subsequently, the volume of water infiltrated during the spring

261 experiments was lower than during the fall tests. Figure 8 shows the relationship between the

262 percentage of water infiltrated and the soil moisture deficit (computed as the difference between

263 the porosity of the soil and initial soil moisture content). The trend is to see a lower volume 
264 infiltrated for initially wetter conditions. Figure 8 indicates there is lower sensitivity of

265 infiltration capacity to soil moisture deficit reduction, which is also linked to a decrease in

266 sorptivity. The data seemed to be relatively constant until a soil moisture deficit of 0.35 , then it

267 rises rapidly at higher soil moisture deficits. For a soil moisture deficit above $\Delta \theta=0.35$ the

268 percentage of water infiltrated appears to follow a linear relationship.

269 To relate the dimensionless parameter $\mathrm{K}_{\mathrm{s}}{ }^{*}$ and soil moisture deficit to percentage infiltration $\left(\mathrm{V}_{\mathrm{i}}{ }^{*}\right)$

270 a log-log multiple regression equation has been developed using the field data, excluding the

271 data from for Site 1 at Hwy 47, where pocket gopher holes were observed:

$272 \quad \mathrm{~V}_{\mathrm{i}}^{*}=\beta_{0} \mathrm{~K}_{\mathrm{s}}^{*}{ }^{\beta 1} \Delta \theta^{\beta 2}$

273 where $\beta_{0}=1.79, \beta_{1}=0.25$, and $\beta_{2}=0.68, \Delta \theta$ is the fraction soil moisture deficit, and $\mathrm{V}_{\mathrm{i}}{ }^{*} \leq 1$

274 Figure 9 shows the goodness of fit of the equation. A correlation coefficient of $0.47(n=28)$ and

275 a slope significantly different from zero $(\alpha=0.05)$ were observed.

\section{Discussion}

\subsection{Analysis of the Experimental Design Parameters}

278 The three different boundary flux rates used (Table 1), were based on the correspondent return

279 periods (T) of 1-year, 2-year and 10-year in the Minneapolis-St. Paul metropolitan area,

280 Minnesota, USA (Perica et al., 2013). Additionally, the field tests were designed to investigate

281 the processes that are believed to be the most significant in infiltration and runoff. There are

282 differences in conditions between what could occur during a real storm event and what occurred

283 in the controlled field tests. A list of those differences is given below.

284 - The rainfall that would be occurring on the side slope in a real event was not considered in the 
field tests. The initial soil moisture deficit is overestimated because of the lack of prewetting of the soil by rainfall incident directly on the side slope surface. Additionally, the added volume due to direct rainfall could spread the fingers and consequently reduce the concentration of flow on the side slope, increasing the fraction of wetted area over time. This effect would be greater downslope and for high flows. Overall, the direct rainfall would be expected to decrease the volume of road runoff infiltrated.

- The water supply container was placed downslope of the shoulder. However, many shoulders consist of gravel and compacted soil, and some water will infiltrate into the shoulder material. This effect will reduce the actual intensity of flow entering the side slope to a

294 value below the intensities associated with the given event return periods, and will 295 increase the fraction of infiltrated road runoff.

- The initial abstraction of water that would be retained on the surface of the road is not taken into account. Again, this effect will reduce the actual intensity of flow entering the side

- Natural decaying organic matter on the side slope surface will absorb some fraction of the 301 direct precipitation and road discharge. The presence of organic matter would decrease 302 the amount of road runoff that reaches the bottom of the filter strip.

303 - The rainfall intensity over the road surface and runoff from the road was assumed to be 304 constant and to flow directly to the side slope without a lag time (the time of 305 concentration was assumed to be zero). Incorporating a lag time would increase the 306 fraction of infiltrated road runoff.

307 - The road discharge was imposed as a uniform sheet flow at the location where it entered the 
side slope. In the actual field situation it is likely that runoff from the road will not enter uniformly onto the side slope. This will have a variable impact on runoff.

310 These effects are not being considered because the focus of this research was on infiltration of 311 road runoff into the slope. Based on our results, we believe that this infiltration is a significant 312 portion of the infiltration into most roadside swales.

\subsection{Importance of Soil Moisture and $K_{\text {sat }}$ Measurements}

314 The soil textures (Table 2) of the roadside filter strips soils correspond to hydrologic soils groups

315 (HSGs) A, B and C; however, the $K_{\text {sat }}$ values estimated correspond to values close to or above 316 the lower end of HSG A, $3.6 \mathrm{~cm} / \mathrm{h}$ (NRCS, 2009) with a small variance. Lee, et al. (2016) have

317 found that soil texture is a "poor" predictor of infiltration performance. It is particularly

318 interesting that at Hwy 13, with a loam/sandy clay loam soil texture type corresponding to an

319 HGA B/C soil, measured $K_{\text {sat }}$ corresponds to a HSG A soil. In the field, it was observed that the 320 clay did not exist as a layer within the soil profile, but was heterogeneously distributed in

321 aggregates, allowing infiltration around the clay. Furthermore, it is important to highlight that

322 after 30 years receiving road runoff these roadside filter strips were not clogged with sediment.

323 The high $K_{\text {sat }}$ of the soil was probably high due to the macropores generated by vegetation roots,

324 activity of macrofauna (e.g. earthworms), and roadside construction/maintenance procedures.

325 The behavior in Figure 8, where percentage infiltration rises rapidly at higher soil moisture

326 deficits, is not consistent with a sorptivity-based infiltration model from infiltration theory. That

327 theory shows that as the moisture deficit increases, the infiltration capacity approaches a

328 maximum value asymptotically. Instead, the plot shows the infiltration capacity increasing

329 without apparent bound as the moisture deficit increases. The high soil moisture deficit values 
occurred in fall 2014, and the percentage infiltration difference between seasons (fall and

331 spring), for the same boundary flux, might be explained by a series of factors related to soil

332 structure, changes in macropores and temperature, and surface sealing. Each of these factors has

333 been analyzed taking into account the measured and observed characteristics of the sites studied.

334 Soil cracking due to aggregate formation during wet-dry cycles takes place in soils containing

335 high percentage of clay (Beven and German, 1982; Preston et al., 1997). Soils with more than

$33615 \%$ of clay content exhibit aggregate structure (Horn et al., 1994, Jarvis, 2007), however the

337 soils in this study had $5 \%$ or less percentage of clay content. In addition, no surface cracks were

338 observed in the field. Freeze-thaw cycles would not explain the observed decreased percentage

339 infiltration during spring since these would likely increase the hydraulic conductivity after winter

340 (Chamberlain and Gow, 1979: Zimmie and LaPlante, 1990). The temperature during the spring

341 tests was higher (an average of $13.5 \mathrm{~F}$ higher) than in the fall tests. Therefore the viscosity of

342 water was lower in spring, which would result in higher infiltration rates; this effect does not

343 justify the trends seen on Figure 8. There are two phenomena that might explain the decrease in

344 infiltration percentage during spring: seasonal changes in roots and surface sealing. During fall

345 with drier weather conditions roots are dying, leaving voids in the soil (Fisher et al., 2015);

346 therefore, infiltration capacity could have been increased (Gish and Jury, 1983; Mitchel et al.,

347 1995; Beven and German, 2013) during the fall tests. On the other hand, during spring, the new

348 fine growing roots can clog soil pores and decrease infiltration capacity (Fisher et al., 2014;

349 Barley, 1954). Finally, the reduction of infiltration capacity after the fall tests may be due to

350 surface sealing (Moore, 1981; Singer and Le Bissonnais, 1998; Gomez and Nearing, 2005).

351 There are two types of rainfall-induced surface seals: structural seals (related to raindrop impact

352 and sudden wetting), and sedimentary seals (result from settling of fine particles carried by 
353 runoff). Dense vegetation protects the surface of the swales from structural seals, since raindrop

354 energy is mitigated before impacting the soil surface. However, during the fall experiments the

355 vegetation was cut, and the slope surface was exposed to rain drop impact afterwards, increasing

356 the possibility of surface sealing development.

357 The lack of a substantial percentage infiltration difference between the medium flux and low flux

358 experiments in the spring implies a change in the soil condition in the latter of the two

359 experiments. There are two hypotheses to explain this outcome. First, the kaolinite particles

360 suspended in the water could have precipitated and clogged soil pores. The latter tests would

361 have started with an initially partially sealed surface, causing the infiltration rates to be lower

362 than in the first experiment. A similar situation was previously observed in filter strip field tests

363 by Deletic and Fletcher (2006) with sediment with a median diameter of $50 \mu \mathrm{m}$. However the

364 particle size of $0.5 \mu \mathrm{m}$ in the present study is likely too small to clog the larger and more

365 influential pores.

366 Second, an incomplete drainage could have occurred between experiments. Typically, two days

367 of drainage occurred between the tests at each site. On swale side slopes the soil is compacted at

368 a depth of $20-30 \mathrm{~cm}$ during construction so that the saturated hydraulic conductivity is

369 significantly smaller than at the surface. Water draining from a given infiltration experiment will

370 be impeded by the lower permeability layers, with an increase soil moisture and thereby increase

371 the wetting front potential (decrease the wetting front suction) at depth. Per infiltration theory,

372 such as with the Green and Ampt model, this will then reduce the infiltration capacity of the soil

373 for subsequent infiltration tests. In the experiments conducted we measured the initial water

374 content of only the surface layer of soil and therefore do not have evidence for this reduction in

375 wetting front suction. Although the saturated hydraulic conductivity would be unchanged, the 
376 soil moisture would have needed further characterization at depth due to the two-layer impact on

377 soil moisture content. We believe that the second hypothesis is the more likely explanation for

378 the reduction on infiltration.

\subsection{Comparison to Previous Research}

380 The results of this study are best compared with filter strip studies. The differences would be the

381 higher slope of the side slopes in a roadside swale and the attention to the measurement of $K_{\text {sat }}$ in

382 this study, without the need for calibration. Deletic and Fletcher (2006) used synthetic runoff

383 applied upslope of a grass strip that was $5 \mathrm{~m}$ long, (comparable to the $4 \mathrm{~m}$ side slopes considered

384 in this study) with a $7.8 \%$ average longitudinal slope, and $0.3 \mathrm{~m}$ width. The initial soil moisture

385 content was not measured and the tests were classified as initially wet or dry. A simplified

386 double-ring infiltrometer test was used to get an estimation of the saturated hydraulic

387 conductivity $(0.72-3.6 \mathrm{~cm} / \mathrm{h})$. However, after calibration to match the measured infiltration at the

388 plot scale, the $K_{s a t}$ values were assumed to be in the range of: $3.6-27 \mathrm{~cm} / \mathrm{h}$. The range and

389 magnitude of $K_{\text {sat }}$ values were greater than the ones observed in the roadside swales of this study

$390(3.47-5.74 \mathrm{~cm} / \mathrm{h})$. The boundary fluxes utilized by Deletic and Fletcher were $3.3 \times 10^{-4}, 6.7 \times 10^{-4}$,

391 and $1 \times 10^{-3} \mathrm{~m}^{2} / \mathrm{s}$, the first being similar to the high flux in this study $\left(3.1 \times 10^{-4} \mathrm{~m}^{2} / \mathrm{s}\right)$,

392 corresponding to a 10-year storm; the other two fluxes were two and three times greater, possibly

393 because they were designed to simulate a more concentrated flow. The runoff coefficients

394 (ROCs) obtained in the cases where the inflow water was mixed with sediment were 0.38 (dry

395 conditions) and 0.67 (wet conditions); these results are lower than the 0.88 ROC values observed

396 in the field experiments presented here for a similar flux. The difference in $K_{\text {sat }}$ is the main

397 reason for the dissimilar results obtained. 
In the experiments by Liu et al. (2016) two newly constructed sloped grassed field scale plots with $17 \%$ and $33 \%$ slopes, $5 \mathrm{~m}$ long were studied applying water from an upstream water distributor. The soil moisture content was not reported. $K_{\text {sat }}$ values were measured using the 401 constant head method (16.1 and $17.7 \mathrm{~cm} / \mathrm{h}$ for each slope, respectively). The boundary fluxes 402 applied were $1.3 \times 10^{-4}$ and $1.7 \times 10^{-4} \mathrm{~m}^{2} / \mathrm{s}$, similar to the medium flux used in this study $\left(1.55 \times 10^{-4}\right.$ $\left.403 \mathrm{~m}^{2} / \mathrm{s}\right)$. These parameters correspond to $\mathrm{K}_{\mathrm{s}}^{*}$ in the range of $1.34-1.97$, which is approximately 2 404 to 13 times greater than the $\mathrm{K}_{\mathrm{s}}{ }^{*}$ observed in this study (Figure 7). In addition, they found 405 saturated hydraulic conductivity and the ROC had a -0.97 correlation coefficient, which indicates 406 the importance of $\mathrm{K}_{\mathrm{s}}{ }^{*}$. The average ROC for both side slopes was 0.07 , five to nine times lower 407 than the ROC values of 0.37 (fall) and 0.6 (spring) observed in the field tests presented in this 408 study. These results are not surprising since the $K_{\text {sat }}$ values estimated by Liu et al. were 409 approximately three times greater than the ones estimated in the highways studied in this 410 research.

411 In contrast to the other studies presented using synthetic runoff, the field tests reported in this 412 study show the response to a wide range of boundary fluxes, including both high and low flows, 413 representing typical intensities for which roadside filter strips in swales are designed and utilized 414 to improve surface water quality. Measurement of the initial soil moisture has been found to be 415 important to compare the soil's infiltration performance. In addition, the percentage of wetted 416 area was estimated in all tests, providing information about flow concentration in grassed 417 roadside swales under different runoff fluxes. Furthermore, measuring $K_{\text {sat }}$ in the field is 418 essential since the soil texture is not a good proxy (Lee et al., 2016). Multiple measurements of $419 K_{\text {sat }}$ are necessary due to its spatial variability (Asleson et al., 2009; Olson et al., 2013; Ahmed et 420 al., 2015); and 10 measurements per site were taken in these field tests. Finally, these 
421 experiments were performed in roadside swales that are 30-50 years-old, therefore the infiltration

422 capacity estimated corresponds to the long-term infiltration of these stormwater control

423 measures.

\section{5. Conclusions}

425 A total of thirty-two tests were performed during three seasons on four different highways 426 located in the Minneapolis-St. Paul metropolitan area, Minnesota, USA to analyze the infiltration

427 performance of roadside filter strips and the effect of fractional coverage of water on infiltration.

428 This study assists the evaluation of vegetated roadside filter strips located on the side slope of

429 swales as stormwater control measures. The channel portion of a roadside swale has typically

430 been the main element believed to control and reduce stormwater runoff, however the side slope

431 shows great potential for runoff infiltration.

432 All the tests indicated that water flow on the lateral slope of a roadside swale is concentrated in

433 fingers, instead of sheet flow, at the typical rainfall/runoff intensities for which infiltration

434 practices are utilized to improve surface water quality. The minimum fraction wetted detected

435 was $54 \%$ and maximum $88 \%$, with an average of $72 \%$ and standard deviation of $9 \%$. A linear

436 relationship between flux of water from the road and fraction wetted was observed, for the

437 intensities tested. Due to the maintenance procedures followed by the Minnesota Department of

438 Transportation, the surface of the side slopes was relatively smooth with no prominent

439 topographical features or signs of erosion; this was supported by low random roughness (RR)

440 measurements.

441 Despite the initial compaction during construction, the saturated hydraulic conductivity of the 442 swales soil was high, relative to the values typical of laboratory permeameter measurements for 
443 the type of soil. This is believed to be due to the macropores generated by vegetation roots,

444 activity of macrofauna (e.g. earthworms), and construction/maintenance procedures. An average

445 of $1.9 \mathrm{~cm}$ of runoff from a typical two-lane highway was infiltrated during the experiments,

446 indicating a high potential for side slope infiltration in these swales.

447 The trend was to have more infiltration when the saturated hydraulic conductivity was higher and

448 for a greater side slope length, as expected. The vegetation cover, type of soil and length of the

449 side slope would be important to consider for constructing roadside swales that will be efficient

450 in stormwater management. The volume infiltrated during spring for the same intensity (medium

451 flux) was on average $12 \%$ lower than in fall due to the larger initial soil moisture content in the

452 spring. Finally, a log-log regression equation has been developed that relates percentage of water

453 influx infiltrated with a dimensionless saturated hydraulic conductivity parameter $\left(\mathrm{K}_{\mathrm{s}}{ }^{*}\right)$ and soil

454 moisture deficit. This equation can provide an estimate of percentage infiltration in the side

455 slopes of roadside swales, which is often the most important means of infiltration because of

456 their area relative to the channel of the swales.

\section{Acknowledgments}

458 The writers are grateful to the Minnesota Department of Transportation and Minnesota Local

459 Road Research Board for funding this research under Contract No. 99008- 97, with Barbara

460 Loida as Technical Liaison. We also thank David Liddell for his help on the field experiments.

461 J.L. Nieber's effort on this project was partially supported by the USDA National Institute of

462 Food and Agriculture, Hatch/Multistate project 12-059. 


\section{References}

465 Abida H. and Sabourin, J. F. (2006). Grass swale-perforated pipe systems for stormwater management.

466 Journal of Irrigation and Drainage Engineering, 132(1): 55-63.

467 Ahearn, D. and Tveten, R. (2008). Legacy LID: Stormwater Treatment in Unimproved Embankments

468 Along Highway Shoulders in Western Washington, International Low Impact Development

469 Conference, November 16-19, 2008, Seattle, WA.

470 Ahmed, F., Gulliver, J. S., and Nieber, J. L. (2015). Field Infiltration Measurements in Grassed Roadside

471 Drainage Ditches: Spatial and Temporal Variability. Journal of Hydrology, 530(11): 604-611.

472 Ahmed, F., Nestingen, R., Nieber, J. L., Gulliver, J. S., and Hozalski, R. M. (2014). A Modified Philip-

473 Dunne Infiltrometer for Measuring the Field-Saturated Hydraulic Conductivity of Surface Soil.

$474 \quad$ Vadose Zone Journal. Vol. 13 No. 10. doi:10.2136/vzj2014.01.0012.

475 Alestra, S. and Battiatto, S. (2008). Fuzzy Image Processing. Implementazione di plug-in per l'ambiente

476 ImageJ. Universita di Catania, Departimento di Matematica e Informatica. Internet, url:

$477 \quad$ http://svg.dmi.unict.it/iplab/imagej/Plugins/Fuzzy\%20Image\%20Processing/downloads/Fuzzy\%20Ima

478 ge\%20Processing\%20-\%20Implementazione\%20di\%20plug-in\%20per\%201'ambiente\%20ImageJ.pdf

$479 \quad$ (accessed April 6, 2016).

480 Allmaras, R. R., Burwell, R. E., Larson, W. E., and Holt, R. F. (1966) Total porosity and random

481 roughness of the interrow zone as influenced by tillage. USDA Conservation Research Report 7 ,

482 USDA, Washington, DC.

483 Asleson, B. C., Nestingen, R. S., Gulliver, J. S., Hozalski, R. M. and Nieber, J. L. (2009) Performance

484 Assessment of Rain Gardens, Journal of the American Water Resources Association, 45: 1019-1031. 
ASTM D2216-10 (2010), Standard Test Methods for Laboratory Determination of Water (Moisture) Content of Soil and Rock by Mass, ASTM International, West Conshohocken, PA.

ASTM D2937-10 (2010), Standard Test Method for Density of Soil in Place by the Drive-Cylinder

ASTM D422-63 (2007)e2, Standard Test Method for Particle-Size Analysis of Soils, ASTM International, Method, ASTM International, West Conshohocken, PA.

ASTM D6913 (2009). Standard test methods for particle size distribution (Gradation) of soils using sieve analysis, D18.03. ASTM International, West Conshohocken, PA.

Barley, K. P. (1954). Effects of root growth and decay on the permeability of a synthetic sandy loam. Soil $494 \quad$ Science, 78: 205-210.

Barrett, M. E., Keblin, M. V., Walsh, P. M., Malina, J. F., and R. B. Charbeneau, (1998). Evaluation of the performance of permanent runoff controls: summary and conclusions, Center for Transportation Research, University of Texas at Austin, TX.

Beven, K. J., and P. F. Germann (1982). Macropores and water flow in soils, Water Resources Research, 18(5): 1311-1325.

Beven, K. J. and Germann, P. F. (2013). Macropores and water flow in soils revisited. Water Resources Research, 49: 3071-3092.

Caltrans (2003) Roadside Vegetated Treatment Sites (RVTS) Study Final Report, Report \# CTSW-RT03-028, California Department of Transportation, 1120 N St., Sacramento, CA., Nov. 2003.

504 Chamberlain, E. J., and Gow, A. J. (1979). Effect of freezing and thawing on the permeability and $505 \quad$ structure of soils. Engineering Geology, 13: 73-92. 
Deletic, A. and Fletcher, T. D. (2006). Performance of grass filters used for stormwater treatment-a field and modelling study. Journal of Hydrology, 317(3-4): 261-275.

508 Fischer, C., Roscher, C., Jensen, B., Eisenhauer, N., Baade, J., Attinger, S., Scheu, S., Weisser, W. W., 509 Schumacher, J., Hildebrandt, A. (2014). How do earthworms, soil texture and plant composition affect $510 \quad$ infiltration along an experimental plant diversity gradient in grassland? PLoS One 9(6): e98987.

511 Fischer, C., Tischer, J., Roscher, C. et al. (2015). Plant species diversity affects infiltration capacity in an 512 experimental grassland through changes in soil properties. Plant Soil, 397: 1-16.

513 Gish T. J, Jury, W. A. (1983). Effect of plant root channels on solute transport. Transactions of the 514 American Society of Agricultural Engineers, 26: 440-444.

515 Gomez, J. A. and Nearing, M. A. (2005). Runoff and sediment losses from rough and smooth soil 516 surfaces in a laboratory experiment. Catena, 59(3): 253-266.

517 Green, W. H. and Ampt, G. (1911). Studies of soil physics, part I - the flow of air and water through $518 \quad$ soils. Journal of Agricultural Science 4: 1-24.

519 Horn, R., Taubner, H., Wuttke, M. and Baumgartl, T. (1994). Soil physical properties related to soil $520 \quad$ structure. Soil and Tillage Research, 30: 187-216.

521 Hunt, W. F., Hathaway, J. M., Winston, R. J., and Jadlocki, S. J. (2010). Runoff Volume Reduction by a 522 Level Spreader-Vegetated Filter Strip System in Suburban Charlotte, N.C. Journal of Hydrologic $523 \quad$ Engineering, 15(6): 499-503.

524 Jarvis, N. J. (2007). A review of non-equilibrium water flow and solute transport in soil macropores: 525 Principles, controlling factors and consequences for water quality. European Journal of Soil Science, $526 \quad 58: 523-546$. 
527 Knight, E. M. P., Hunt, W. F., and Winston, R. J. (2013). Side-by-side evaluation of four level spreader528 vegetated filter strips and a swale in eastern North Carolina. Journal of Soil and Water Conservation, $529 \quad 68(1): 60-72$.

530 Lancaster, C. D. (2005). A Low Impact Development Method for Mitigating Highway Stormwater

531 Runoff - Using Natural Roadside Environments for Metals Retention and Infiltration. Masters Thesis, 532 Washington State University, Department of Civil and Environmental Engineering, Pullman, $533 \quad$ Washington, USA.

534 Le Bissonnais, Y., Lecomte, V., and Cerdan, O. (2004). Grass strip effects on runoff and soil loss. 535 Agronomie, EDP Sciences, 24 (3): 129-136.

536 Lee, R. S., Traver, R. G. and Welker, A. L. (2016). Evaluation of soil class proxies for hydrologic 537 performance of in situ bioinfiltration systems, Journal of Sustainable Water in the Built Environment, $538 \quad 04016003$.

539 Liu, Y., Hu, J., Wang, T., Cai, C., Li, Z., and Zhang, Y. (2016). Effects of vegetation cover and road540 concentrated flow on hillslope erosion in rainfall and scouring simulation tests in the Three Gorges $541 \quad$ Reservoir Area, China. Catena, 136: 118-117.

542 Mitchell A. R., Ellsworth T. R., and Meek, B. D. (1995). Effect of root systems on preferential flow in $543 \quad$ swelling soil. Communications in Soil Science Plant Analysis, 26: 2655-2666.

544 Moore, I. D. (1981). Infiltration Equations Modified for Surface Effects. Transactions of the American 545 Society of Agricultural Engineers, 24:1546-1553.

546 Olson, N. C., Gulliver, J. S., Nieber, J. L., Kayhanian, M. (2013). Remediation to improve infiltration into 547 compact soils. Journal of Environmental Management, 117: 85-95. 
Perica, S., D. Martin, S. Pavlovic, I. Roy, M. St. Laurent, C. Trypaluk, D. Unruh, M. Yekta, G. Bonnin (2013). NOAA Atlas 14 Volume 8, Precipitation-Frequency Atlas of the United States, Midwestern States. NOAA, National Weather Service, Silver Spring, MD.

Poletika, N., Coody, P. N., Fox, G., Sabbagh, G. J., Dolder, S. C., and White, J. (2009). Chlorpyrifos and atrazine removal from runoff by vegetated filter strips: experiments and predictive modeling. Journal of Environmental Quality, 38(3): 1042-1052.

Preston, S., Griffiths, B. S. and Young, I. M. (1997). An investigation into sources of soil crack heterogeneity using fractal geometry. European Journal of Soil Science, 48: 31-37.

Prewitt, J. M. S. and Mendelsohn, M. L. (1966). The analysis of cell images, Annals of the New York Academy of Sciences, 128: 1035-1053.

Rasband W. S. (1997-2014). ImageJ, U.S. National Institutes of Health, Bethesda, MD. Internet, url: imagej.nih.gov/ij/ (accessed January 15, 2016).

Singer, M. J., and Le Bissonnais, Y. (1998). Importance of surface sealing in the erosion of some soils from a Mediterranean climate. Geomorphology, 24(1): 79-85.

U.S. Department of Agriculture (2014). Natural Resources Conservation Service Soil. Internet, url:

$$
\text { December 5, 2015). }
$$

Weiss, P. T. and Gulliver, J. S. (2015). Effective Saturated Hydraulic Conductivity of an InfiltrationBased Stormwater Control Measure. Journal of Sustainable Water Built Environment, Hydrologic Connectivity. Journal of Hydrologic Engineering, Vol.18 (9): 1157-1169. 
570 Zimmie T. F. and LaPlante C. (1990). The effect of freeze-thaw cycles on the permeability of a fine-

571 grained soil. Proceedings of the 22nd Mid-Atlantic Industrial Waste Conference. Drexel University, 572 Pennsylvania: 580-593. 